\title{
Autism Spectrum Disorders: Etiology and Pathology
}

\author{
Ann Katrin Sauer ${ }^{1,2} \bullet$ Janelle E. Stanton ${ }^{1,2} \bullet$ Sakshi Hans $^{1} \bullet$ \\ Andreas M. Grabrucker $1,2,3$ \\ ${ }^{1}$ Cellular Neurobiology and Neuro-Nanotechnology Lab, Department of Biological \\ Sciences, University of Limerick, Limerick, Ireland; ${ }^{2}$ Bernal Institute, University of \\ Limerick, Limerick, Ireland; ${ }^{3}$ Health Research Institute (HRI), University of Limerick, \\ Limerick, Ireland
}

Author for correspondence: Andreas M. Grabrucker, Department of Biological Sciences, University of Limerick, Limerick, Ireland. E-mail: andreas.grabrucker@ul.ie

Doi: https://doi.org/10.36255/exonpublications.autismspectrumdisorders.2021.etiology

\begin{abstract}
Autism spectrum disorders (ASD) are a group of neurodevelopmental diseases. The cause of ASD is unknown, but several genetic and non-genetic risk factors have been characterized that, alone or in combination, are implicated in the development of ASD. Currently, no diagnostic biomarkers are available, and the diagnosis of ASD is based on typical features that include repetitive behaviors, and impaired social communication and interaction. Several pathomechanisms such as alterations in brain development and function, and synaptic defects have been proposed to contribute to these behaviors. In addition, processes outside the central nervous system may contribute to, or modify, the clinical phenotype and severity. This chapter summarizes the clinical features of ASD, highlights the important genetic and non-genetic risk factors for ASD, and introduces the current knowledge around the pathological processes within and outside the brain.
\end{abstract}

Keywords: autism spectrum disorders; etiology; genes; incidence; prevalence; symptoms

In: Autism Spectrum Disorders. Grabrucker AM (Editor). Exon Publications, Brisbane, Australia. ISBN: 978-0-6450017-8-5; Doi: https://doi.org/10.36255/exonpublications. autismspectrumdisorders. 2021

Copyright: The Authors.

License: This open access article is licenced under Creative Commons Attribution-NonCommercial 4.0 International (CC BY-NC 4.0) https://creativecommons.org/licenses/by-nc/4.0/ 


\section{INTRODUCTION}

While "autism" as a term was initially introduced to describe a behavioral symptom of self-withdrawal in schizophrenic patients, psychiatrists Dr. Leo Kanner and pediatrician Dr. Hans Asperger adopted the term autism in the 1940s to introduce a syndrome in children with behavioral differences in social interaction and communication, and restrictive and repetitive interests $(1,2)$. Nowadays, the umbrella term "autism spectrum disorders" (ASD) is used to describe a clinically heterogeneous group of neurodevelopmental disorders that share common behavioral core features affecting social communication and include restrictive and repetitive stereotypic behavioral patterns and interests. The term incorporates several conditions such as idiopathic forms, including autism, Asperger syndrome and Pervasive Developmental Disorder - Not Otherwise Specified, and Childhood Disintegrative Disorder and certain genetic disorders like Rett syndrome, which can exhibit autistic traits (3). With the establishment of the DSM-V (diagnostic and statistical manual of mental disorders, fifth edition), these formerly separate diagnoses were brought under one unifying umbrella as ASD (3) (see chapter 2). Thus, spectrum disorder classification is reflective of the heterogeneous nature of ASD.

\section{CLINICAL FEATURES}

The clinical features historically associated with ASD are the triad of impairments in speech, social interaction, and the presence of repetitive or restricted behaviors. However, ASD are also associated with many co-morbidities, which can be psychological and physiological.

ASD typically start to manifest in childhood and is diagnosed by age 3 in most cases. Early indicators of ASD in childhood (before age 3) include lack of response to one's name and discomfort with maintaining eye contact (4). Most symptoms of ASD persist into adulthood, especially with regards to social functioning and cognitive ability. Symptoms, particularly communication skills, can improve over time as the individual reaches adolescence and adulthood. Intellectual functioning and IQ tend not to change over time. While some features of ASD remain relatively stable, the quality of life of an individual with ASD can be improved by creating a strong social support system or other accommodations and interventions (5).

The clinical diagnosis of ASD is based on the presence of some key features, such as impaired social development, and repetitive behaviors and interests (see chapter 2). Delay in speech development, learning impairment, and difficulties with social interaction are common in ASD. Executive function and organizational skills are notably impacted in individuals with ASD. They commonly tend not to initiate interactions with their environment, particularly social interactions. They also often suffer from difficulties with processing stimuli and planning out the steps of an activity and may display ritualized or rigid behavior patterns. Thus, difficulty with performing independent behaviors and initiating tasks are notable features of ASD. Another area often impacted in ASD is the capacity to generalize skills across different settings. Individuals tend to have difficulty adapting to new environments, persons, and materials, likely due to highly specific stimuli. 
The third core feature of ASD is the presence of repetitive or restricted behaviors. These can be stereotyped actions such as hand flapping and rocking of the body, and verbal behaviors such as repetitive words and phrases. Individuals with ASD also tend to have specific or restricted interests. For example, intense interest in a certain topic, sensory fixations on a particular object, or adherence to a specific routine or method of doing a task (6).

Secondary symptoms of ASD include aggression, hyperactivity, impulsivity, and the occurrence of co-morbidity such as anxiety and depression. A major feature of ASD is the heterogeneity of its clinical features. A diversity of symptoms along with many psychological and physiological comorbidities may be present. Figure 1 illustrates the diversity of these symptoms and comorbidities.

Psychological comorbidities include attention-deficit hyperactivity disorder (ADHD), obsessive-compulsive disorder (OCD), anxiety, and intellectual disability. There is a notable co-occurrence of ADHD with ASD, and the two conditions share many neurological and behavioral similarities. For example, hyperactivity and social deficits are found in both ASD and ADHD. About 30-50\% of persons diagnosed with ASD show symptoms of ADHD as well. The $5^{\text {th }}$ edition of the Diagnostic and Statistical Manual of Mental Disorders takes this into account and now allows for a dual diagnosis of ADHD and autism (7). Conditions such as anxiety and depression often co-occur because of the challenges persons with ASD face in day-to-day life, such as social isolation and difficulty in communication. However, the co-occurrence may also be based on overlapping biological processes disturbed in these disorders. Schizophrenia is also thought to be linked with ASD, and ASD were once considered a childhood form of schizophrenia. The two diseases appear to share some similar features regarding behavior and brain biochemistry, and certain risk factors. Other abnormalities, including aggression and self-harming behaviors, may also be observed in the individual.

Physiological comorbidities of ASD include epilepsy, sleep disorders, and gastrointestinal (GI) problems. Epilepsy and ASD co-occur at a relatively high rate for reasons that are not fully clear, though they are likely due to similar risk factors (for example, prenatal environment) and brain pathologies such as synaptic defects. Interestingly, ASD individuals with intellectual disability are more likely to develop epilepsy than those without intellectual disability (8).

Immune system dysfunction is another comorbidity of ASD with reports showing increases in cytokine levels and inflammation (9). An association between ASD and some autoimmune disorders has long been recognized in scientific literature. Besides, the transfer of maternal autoantibodies to the developing fetal brain, thereby affecting neurodevelopment, was raised as possible contributing factor to the pathogenesis of ASD. In addition, maternal immune activation seems to be a significant risk factor for ASD (10).

The presence of a comorbidity is frequently correlated with more severe autism core symptoms, which, in general, vary from profound, where an autistic person may be non-verbal and unable to function without considerable support, to relatively "high-functioning." Asperger's syndrome was previously considered a highfunctioning form of autism, although this is not believed to be the case now. DSM-V lists Asperger's syndrome under the broad category of ASD. Symptoms of Asperger's tend to be less severe than typical autism, and Asperger's syndrome may manifest later, with one study reporting average age of diagnosis as seven years (11). Individuals with Asperger's usually do not experience a delay in speech 


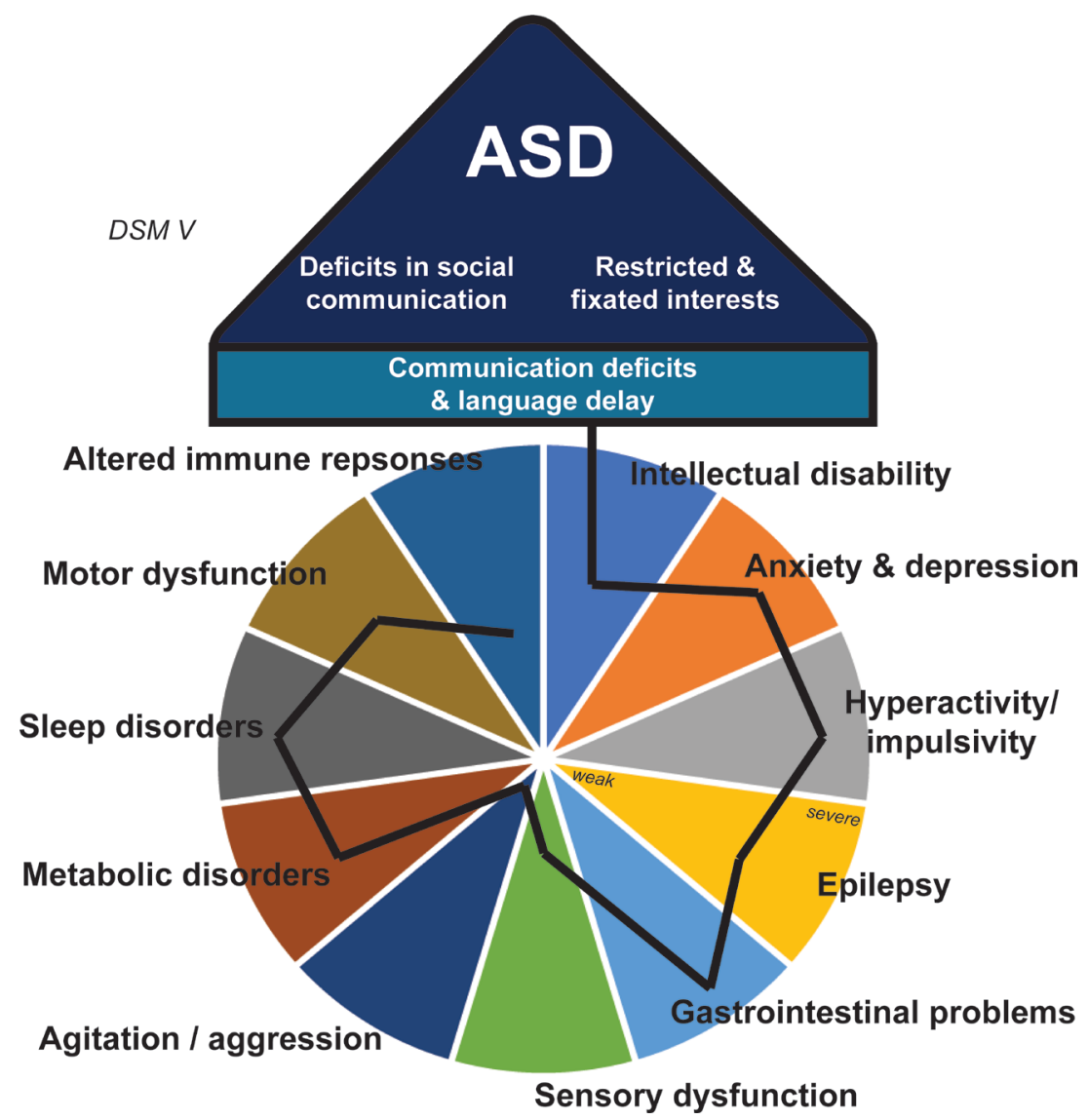

Figure 1. Clinical features of ASD. The three core features of ASD are deficits in social communication, restricted and fixated interests together with speech deficits, and language delays. The first two features are used to diagnose ASD according to the Diagnostic and Statistical Manual of Mental Disorders, 5th Edition. In addition, individuals with ASD may present further symptoms and comorbidities such as cognitive deficits (intellectual disability), anxiety, depression, attention deficits and hyperactivity, impulsivity, seizures, gastrointestinal problems, sensory dysfunction, aggression, metabolic disorders, sleep disorders, motor dysfunction, and altered immune responses. However, not all symptoms and comorbidities are present in individuals with ASD, and those that are, vary in severity. This results in a considerable heterogeneity of clinical features of individuals with ASD.

development and have average to above-average intelligence. However, symptoms such as significant impairment in social interaction and restricted behaviors and interests are shared with other ASD (12).

Taken together, there is considerable variability and heterogeneity in ASD regarding its clinical features and co-occurring conditions. These comorbidities can affect different areas of functioning and body systems, ranging from physiological to psychiatric. 


\section{ETIOLOGY}

The etiology of ASD is likely to be multifactorial, with both genetic and nongenetic factors playing a role (Figure 2). ASD can be syndromic or non-syndromic. Syndromic ASD is often associated with chromosomal abnormalities or monogenic alterations. Such examples include Rett syndrome, fragile X syndrome, and MECP2 duplication syndrome (13). Contrary to syndromic ASD, the etiology of non-syndromic ASD is still relatively undefined due to its genetic heterogeneity. A collaboration of de novo mutations and prenatal plus postnatal environmental factors are likely to play a role.

\section{Distribution}

According to the Centre for Disease Control and Prevention Agency, USA, figures in the United States show that 1 in 54 children are currently identified with ASD. According to a study undertaken during 2009-2017, approximately 17\% of children between the ages of 3-17 have an established developmental disability, such as autism and attention-deficit disorder (14). European studies have had fluctuating results throughout the years due to alterations in diagnostic criteria. A large study carried out titled "Autism Spectrum Disorders in Europe" included 14 countries. Amongst them were Spain, Italy, Ireland, France, Belgium, and Poland. The priority was to estimate the prevalence of ASD in children ranging from 7-9 years in 2015 using nationwide registries and regional statistics. Results varied dramatically with a prevalence of 4.76/1,000 in South-East France and 31.3/1000 in Iceland. Ad hoc analyses with shared protocols were carried out in multiple countries, including Ireland and Italy. As of now, only the results gathered from Italy have been published, estimating an ASD prevalence of 7.99/1,000 (15). Furthermore, a meta-analysis focused on the prevalence of ASD in the South, East, and Western parts of Asia has identified East Asia (including South Korea and China) with the highest prevalence with 51/1000, followed by West Asia with 3.5/1000 and South Asia with 3.1/1000 (16).

However, the prevalence of ASD is still not well defined, with multiple studies across the globe identifying significantly higher figures in different countries and continents. Additionally, case figures in low-income countries are not definitive due to a lack of assessment and diagnostic tools. The latest statistics from 2020 suggest Hong Kong, South Korea, United States, Japan, and Ireland hold the highest prevalence of cases, whereby 372 in 10,000 children in Hong Kong have an ASD (17). An increase in ASD diagnoses has been reported in several countries over the last decade. For example, studies on autism carried out in the 1960s throughout Europe and the United States portrayed ASD as a rare disorder with the prevalence ranging from 2 to 4 children out of 10,000. While this may be linked to increased awareness and a change in diagnostic criteria, the contribution of environmental factors, although not well characterized, cannot be excluded.

Further to this, a gender difference was observed, with boys more likely to have a form of autism than girls. Reports suggest ASD is four times more frequent in boys than in girls (18). However, current studies suggest that this ratio is at least partly due to underdiagnosis of females with ASD, especially at young age. In line with this, the average age of diagnosis is higher in females. 


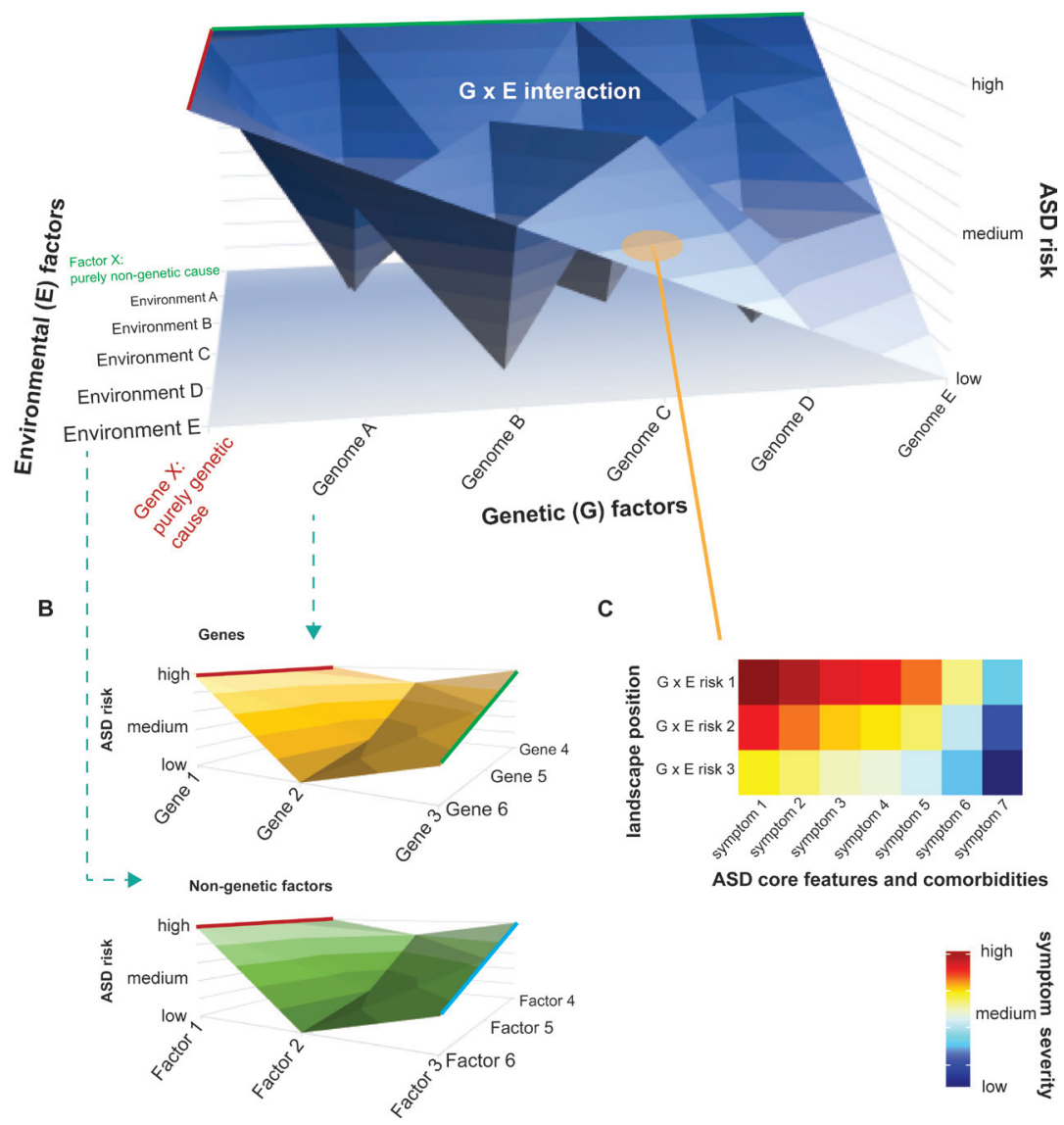

Figure 2. Model for the etiology of ASD. A. ASD are caused by genetic or environmental factors or a combination of these. For some individuals, ASD is solely caused by the presence of the genetic mutation(s) (red line). Exposure to a certain environment may cause ASD independent of the genetic background in some individuals (green line). In most cases, the genetic setup of an individual will, in combination with the exposure to environmental factors, determine the risk for ASD. For example, while a person with genome A may be at low risk in environment $A$, the same person may have high risk in environment $E$. B. Each genome and each environment is a combination of many genetic factors (upper panel) and non-genetic factors (lower panel), respectively. Whether a genome confers a high risk of developing ASD may be determined by a single mutation, i.e., as seen in many syndromic forms of ASD (red line), or a combination of gene variants, where ASD-associated variants may act in a simple additive way (green line) or are in a more complex relationship. For example, the ASD-associated gene 3 may result in low risk if in combination with gene 6 , but the risk increases in the presence of gene 5. Thus, multiple variants will increase ASD risk, but specific gene variants may also decrease the overall risk. Similarly, the presence of one particular environmental factor may be such a strong trigger that it acts independently of other environmental factors (red line). In many cases, however, a combination of environmental factors will determine the overall risk contributed through non-genetic factors in an additive or more complex relationship. C. In case the risk of developing ASD surpasses a threshold, the genetic factors, environmental factors, and their interplay will determine the severity of ASD symptoms and the presence and severity of comorbidities. This results in considerable heterogeneity among ASD. 
Gender differences in the presentation of ASD have been heavily studied with few significant results, although some comorbidities such as depression, sensory issues and seizures may be more frequent in females, further obscuring ASD diagnosis (19).

\section{Genetic factors}

ASD is considered a complex genetic disorder with high heritability. Epidemiological twin studies support the strong genetic component of ASD. The concordance rate for identical twins is $70-90 \%$ and fraternal twins is $0-10 \%(20)$. In families with existing cases of ASD, familial clustering can be observed. Younger siblings of family members with an ASD diagnosis face an increased risk for ASD, even more so for younger male siblings $(21,22)$. In $20-25 \%$ of children or adults with ASD, genetic causes can be identified in the form of de novo mutations, common and rare genetic variations, and ASD-associated common polymorphisms (20, 23, 24). Overall, the SFARI (Simons Foundation Autism Research Initiative) gene database, a database of autism candidate genes, lists about 1000 genes associated with ASD.

Genes entered into the database are scored based on their strength of association with ASD risk, and are sorted into four different categories: $S$ syndromic, category 1 , category 2 , and category $3(25,26)$. The 126 genes currently listed within category $\mathrm{S}$ include mutations that pose a substantial risk for ASD and additional characteristics outside of the requirements of present symptoms for an ASD diagnosis. Genes found in category 1 have a high confidence rate for their role in ASD. Their implication in ASD is based on the presence of at least three de novo mutation according to literature, inclusion in the SPARK list (27), and for most a false discovery rate threshold under 0.1. To date, 207 genes are included in category 1 . The 211 genes ranked in category 2 are implied to be strong candidates for an association with ASD. To be scored as a strong candidate ASD gene, at least two de novo mutations have to be reported in the literature. The gene of interest should have a genome-wide significance threshold (a threshold that determines the statistical significance of a reported association between a common variant and a given trait), of $\mathrm{p} \leq 5 \times 10^{-8}$, or evidence of a functional effect of the mutation in genome-wide association study (GWAS). Category 3 includes the largest number of genes, 506, ranked as suggestive candidates associated with ASD. For these genes, only a single de novo mutation has been reported, or the gene has been implicated in a GWAS that has not been replicated to date.

\section{Environmental factors}

Non-genetic factors mediating ASD risk could include parental age, maternal nutritional and metabolic status, infection during pregnancy, prenatal stress, and exposure to certain toxins, heavy metals, or drugs. Parental age may be a contributor of genetic mutations. Increased paternal age has been shown to increase the risk of ASD in offspring (28); however, some studies have rejected this hypothesis (29). Maternal nutritional status throughout pregnancy is a critical component for normal brain development. An excess, or a deficit, of micronutrients such 
as folic acid, zinc, iron, vitamin D, and omega-3 may lead to impaired neurodevelopment. Comparative studies have found a higher risk of ASD in children who develop under folic acid deficient conditions (30). However, an excess of folic acid also leads to neurocognitive impairments. Trace metal dyshomeostasis has also been shown to affect brain development and is linked to ASD (31). In particular, the accumulation of toxic metals such as mercury and lead, and the lack of the essential metal zinc during pregnancy has been linked to ASD in epidemiological and animal studies.

Another non-genetic factor increasing the risk for ASD is maternal infection (32). Following the association between congenital rubella infections and ASD development, the role of immune activation and infections has been under constant review. However, the focus has shifted to the maternal immune response an infection may provoke, including inflammation and cytokine activation. Maternal immune activation studies are currently carried out on animal models such as mice and rhesus macaques. Several hypotheses have been proposed whereby maternal cytokines may shift to the placenta leading to inflammation and excess cytokine production in the fetus and may result in gene dysregulation. Maternal antibody exposure studies on rhesus macaques have corroborated a common endophenotype of ASD through maternal immune activation, leading to increased brain growth and total cerebral volume in the offspring (33). Studies show that inflammatory abnormalities are not restricted to gestation but persist outside of the womb into adulthood, with multiple studies reporting abnormal adaptive and innate immune function in individuals with ASD. For instance, elevated chemokine and cytokine levels have been detected in the central nervous system and peripheral blood (34-36). Activation of astroglia and microglia cells alongside increased proinflammatory cytokine levels throughout life suggests a neuroinflammatory phenotype in ASD that might play a significant role in the induction of ASD behavior (36).

Maternal medicinal use during pregnancy, especially those used to counteract epilepsy and depression, has been correlated with the risk of ASD. Studies have implicated maternal valproate use with several neurodevelopmental alterations in the offspring, including ASD, though indications suggest it is dose related. Antidepressant use during pregnancy, including selective serotonin reuptake inhibitors, can increase the risk of ASD development; however, conflicting results have also been found (37).

While most of the data on paternal factors are based on epidemiological studies, maternal immune activation and prenatal zinc deficiency have been modeled in animals and identified as potentially causative factors, and the underlying mechanisms have been investigated (38). Additionally, various environmental factors increase the risk of co-morbidities, for example, gastrointestinal disorders, epilepsy, and obesity (30).

\section{PATHOLOGY OF ASD}

For many years, brain development and function have been the focus of research in ASD. Experimental and postmortem studies have identified central nervous system (CNS) pathologies at gross morphological level and cellular level, for 
example, in neurons and glial cells. From these studies, it can be concluded that neuropathologies are evident in ASD. However, research in recent years on immune responses and gut-brain signaling (38) have revealed that pathologies in ASD also exist outside the CNS.

\section{Neuropathology}

Several studies have reported abnormalities such as increased head circumferences and intracranial volumes in children aged $1-4$, who were later diagnosed with ASD (39). A meta-analysis of volumetric studies investigating the brain structure of young individuals with ASD found alterations in the lateral occipital lobe, the pericentral region, the medial temporal lobe, the basal ganglia, and proximate to the right parietal operculum (40); however, in older individuals with ASD, the previously reported anatomical abnormalities such as larger intracranial volumes, smaller cerebellar volumes, larger amygdala volumes, or altered volumes of the corpus callosum and hippocampus were not confirmed using large sample sizes obtained from the Autism Brain Imaging Data Exchange (ABIDE) database (39). Thus, it has been proposed that early brain overgrowth in ASD is followed by a phase of growth arrest during development or even degeneration (41). In addition, the reported gross anatomical abnormalities cannot be directly linked to clinical phenotypes of individuals with ASD.

Brain connectivity was reported to be different in individuals with ASD. Lower connectivity between distal brain regions and increased connectivity within proximal brain regions has been found. However, there is conflicting data, and several studies could not confirm this finding (42).

Abnormalities have also been reported in the cytoarchitecture of the brain of individuals with ASD. For example, a decreased number of cerebellar Purkinje cells was found in ASD brains (43). However, the clearest neuropathology of ASD is synaptic dysfunction. Many of the 207 SFARI genes associated with high risk (syndromic and category 1) for ASD encode for proteins that play a crucial role in synaptic function in the brain. Widely recognized and well-published high-risk candidates for ASD susceptibility include members of the SHANK (SH3 and multiple ankyrin repeat domains) family of postsynaptic scaffolding proteins (i.e., SHANK2/3) (43-46), the cell adhesion family of neurexins (i.e., NRXN1) (47-49), and neuroligins (i.e., NLGN2, NLGN4X) (50-53). Based on in vitro and in vivo models with genetic manipulations, numerous ASD-associated genes were found to be involved in pathways responsible for protein synthesis and degradation, chromatin remodeling, and synaptic function, ultimately converging in their role in synaptic homeostasis and synaptic plasticity (54-56). Therefore, ASD is also classified as a synaptopathy (57). At synapses, two signaling pathways seem to be critical to the ASD pathology. The mTOR/PI3K pathway that is particularly associated with syndromic ASD and the NRXN-NLGN-SHANK pathway (58, 59). Together, these pathways are key regulators of synaptogenesis. However, their presence is vastly limited to excitatory synapses, which ultimately may result in an imbalance between excitatory and inhibitory transmission. It has been speculated that many genetic and non-genetic risk factors for ASD mechanistically converge at synaptic level (60). 


\section{Extracerebral pathology}

Beyond the brain, in recent years, researchers started to investigate the role of other organ systems altered in ASD. One system that has been heavily implicated in ASD is the GI system, with many individuals with ASD reporting GI dysfunction. Reports about the prevalence of GI disturbances within the autistic population vary between studies, with estimates ranging between 20-86\% (61). Besides GI dysfunction being more prevalent in individuals with ASD than in non-autistic individuals, the severity of GI abnormalities seems to be correlated with the severity of ASD (62), pointing towards a potential role of the GI system as modifier of ASD behavior and a factor in ASD etiology (63). GI symptoms like abdominal pain, bloating, diarrhea, constipation, or gastroesophageal reflux are the most commonly reported GI problems $(64,65)$.

Furthermore, increased intestinal permeability in ASD individuals and animal models of ASD has been reported (66-68), giving rise to the hypothesis of "leaky gut" contributing to chronic inflammation in ASD. Interestingly, barrier dysfunction is also a common feature in inflammatory disorders of the gut such as Crohn's disease, inflammatory bowel disease, and celiac disease, further implicating the role of GI disorders and immune function. In certain genetic forms of autism, mutations in genes affecting the CNS directly affect the gut's enteric nervous system, causing gut dysmotility $(69,70)$.

The gut-microbiome-brain axis has been recognized to modify behavior and play a role in neurodevelopment (71). Dysbiosis of the gut microbiome in individuals with ASD and animal models has been described in many studies. Investigation of the microbiome in ASD subjects versus non-autistic individuals discovered differences in microbial diversity in stool and fecal samples (72-76). Besides abnormal bacterial diversity, individuals with ASD present with an abnormal microbial composition which might exacerbate GI pathology and inflammatory processes (77). Despite conflicting reports due to differences in general methodology, sample size, exclusion or inclusion of participants with known GI dysfunction in the study, and likely difference in diets due to different countries of origin, several studies report changes in Bacteroides and Firmicutes microbiota on phylum level $(72,78-83)$. Furthermore, on phylum level, Actinobacteria in individuals with autism are different compared to control subjects $(73,78,83)$. Changes to gut microbiota and abnormal intestinal epithelial barrier function ("leaky gut") directly or indirectly elicit inflammatory processes that impact cerebral function, thereby contributing to the neuropathology of $\operatorname{ASD}(84,85)$.

\section{CONCLUSION}

ASD are very heterogenous due to complex underlying pathomechanisms triggered by various factors. Some children and adults with ASD are fully able to perform all activities of daily living, while others require substantial support to perform basic activities. To date, the etiology and pathogenic mechanisms remain incompletely understood. However, the presence of common behavioral features that are the basis of ASD diagnosis hints at a core pathology shared by the majority of individuals with the condition. Given that ASD are associated with a substantial 
socioeconomic burden (86), more research investigating the etiology and pathology of ASD is needed to identify possible biomarkers and treatment and prevention strategies, and improve existing therapies. Due to the large heterogeneity, individuals with ASD will highly benefit from a personalized medicine approach.

Acknowledgment: This research was supported by start-up funding from the Faculty of Science and Engineering of the University of Limerick, Ireland.

Conflict of interest: The authors declare no potential conflicts of interest with respect to research, authorship and/or publication of this manuscript.

Copyright and permission statement: The authors confirm that the materials included in this chapter do not violate copyright laws. Where relevant, appropriate permissions have been obtained from the original copyright holder(s), and all original sources have been appropriately acknowledged or referenced.

\section{REFERENCES}

1. Kanner L. Autistic disturbances of affective contact. Nerv Child.1943;2:217-50.

2. Asperger H. Die "Autistischen Psychopathen" im Kindesalter. Arch Psychiatr Nervenkr. 1944;117(1):76-136. https://doi.org/10.1007/BF01837709

3. American Psychiatric Association. Diagnostic and Statistical Manual of Mental Disorders [Internet]. Diagnostic and Statistical Manual of Mental Disorders, 5th Edition. American Psychiatric Association; 2013. https://doi.org/10.1176/appi.books. 9780890425596

4. Masi A, DeMayo MM, Glozier N, Guastella AJ. An Overview of Autism Spectrum Disorder, Heterogeneity and Treatment Options. Neurosci Bull. 2017;33(2):183-93. https://doi.org/10.1007/ s12264-017-0100-y

5. Volkmar FR, Wolf JM. When children with autism become adults. World Psychiatry. 2013;12(1):79-80. https://doi.org/10.1002/wps.20020

6. Kim SH, Lord C. Restricted and repetitive behaviors in toddlers and preschoolers with autism spectrum disorders based on the Autism Diagnostic Observation Schedule (ADOS). Autism Res. 2010;3(4):162-73. https://doi.org/10.1002/aur.142

7. Leitner Y. The co-occurrence of autism and attention deficit hyperactivity disorder in children - What do we know? Front Hum Neurosci. 2014;8:268. https://doi.org/10.3389/fnhum.2014.00268

8. Besag FMC. Epilepsy in patients with autism: Links, risks and treatment challenges. Neuropsychiatr Dis Treat 2018;14:1-10. https://doi.org/10.2147/NDT.S120509

9. Careaga M, Van de Water J, Ashwood P. Immune dysfunction in autism: A pathway to treatment. Neurotherapeutics. 2010;7(3):283-92. https://doi.org/10.1016/j.nurt.2010.05.003

10. Boulanger-Bertolus J, Pancaro C, Mashour GA. Increasing role of maternal immune activation in neurodevelopmental disorders. Front Behav Neurosci. 2018;12:1-6. https://doi.org/10.3389/ fnbeh.2018.00230

11. Mandell DS, Novak MM, Zubritsky CD. Factors associated with age of diagnosis among children with autism spectrum disorders. Pediatrics. 2005;116(6):1480-6. https://doi.org/10.1542/peds.2005-0185

12. Woodbury-Smith MR, Volkmar FR. Asperger syndrome. Eur Child Adolesc Psychiatry. 2009;18(1):2-11. https://doi.org/10.1007/s00787-008-0701-0

13. Sztainberg Y, Zoghbi HY. Lessons learned from studying syndromic autism spectrum disorders. Nat Neurosci. 2016;19(11):1408-18. https://doi.org/10.1038/nn.4420

14. Maenner MJ, Shaw KA, Baio J, Washington A, Patrick M, DiRienzo M, et al. Prevalence of autism spectrum disorder among children aged 8 Years-Autism and developmental disabilities monitoring 
network, 11 Sites, United States, 2016. MMWR Surveill Summ. 2020;69(4). https://doi.org/10.15585/ mmwr.ss6903al

15. Chiarotti F, Venerosi A. Epidemiology of autism spectrum disorders: A review of worldwide prevalence estimates since 2014. Brain Sci 2020;10(5). https://doi.org/10.3390/brainscil0050274

16. Qiu S, Lu Y, Li Y, Shi J, Cui H, Gu Y, et al. Prevalence of autism spectrum disorder in Asia: A systematic review and meta-analysis. Psychiatry Res. 2020;284:112679. https://doi.org/10.1016/j. psychres.2019.112679

17. Autism spectrum disorders [Internet]. [cited 2021 May 14]. Available from: https://www.who.int/ news-room/fact-sheets/detail/autism-spectrum-disorders

18. Rivet TT, Matson JL. Review of gender differences in core symptomatology in autism spectrum disorders. Research in Autism Spectrum Disorders. 2011;5(3):957-76. https://doi.org/10.1016/j. rasd.2010.12.003

19. Ferri SL, Abel T, Brodkin ES. Sex Differences in Autism Spectrum Disorder: a Review. Curr Psychiatry Rep. 2018;20(2):9. https://doi.org/10.1007/s11920-018-0874-2

20. Abrahams BS, Geschwind DH. Advances in autism genetics: on the threshold of a new neurobiology. Nat Rev Genet. 2008;9(5):341-55. https://doi.org/10.1038/nrg2346

21. Genovese A, Butler MG. Clinical assessment, genetics, and treatment approaches in autism spectrum disorder (ASD). Int J Mol Sci. 2020;21(13):1-18. https://doi.org/10.3390/ijms21134726

22. Ozonoff S, Young GS, Carter A, Messinger D, Yirmiya N, Zwaigenbaum L, et al. Recurrence risk for autism spectrum disorders: A baby siblings research consortium study. Pediatrics. 2011;128(3):e488-95. https://doi.org/10.1542/peds.2010-2825

23. Geschwind DH. Genetics of autism spectrum disorders. Trends Cogn Sci. 2011;15(9):409-16. https:// doi.org/10.1016/j.tics.2011.07.003

24. Miles JH. Autism spectrum disorders--a genetics review. Genet Med. 2011;13(4):278-94. https://doi. org/10.1097/GIM.0b013e3181ff67ba

25. About the Gene Scoring Module - SFARI Gene [Internet]. [cited 2021 May 14]. Available from: https:// gene.sfari.org/about-gene-scoring/

26. Gene Scoring Module - SFARI Gene [Internet]. [cited 2021 May 14]. Available from: https://gene.sfari. org/database/gene-scoring/

27. Satterstrom FK, Kosmicki JA, Wang J, Breen MS, De Rubeis S, An J-Y, et al. Large-Scale Exome Sequencing Study Implicates Both Developmental and Functional Changes in the Neurobiology of Autism. Cell. 2020;180(3):568-584.e23.

28. Wu S, Wu F, Ding Y, Hou J, Bi J, Zhang Z. Advanced parental age and autism risk in children: a systematic review and meta-analysis. Acta Psychiatr Scand. 2017;135(1):29_41. https://doi.org/10.1111/ acps. 12666

29. Karimi P, Kamali E, Mousavi SM, Karahmadi M. Environmental factors influencing the risk of autism. J Res Med Sci 2017;22: 27. https://doi.org/10.4103/1735-1995.200272

30. Emberti Gialloreti L, Mazzone L, Benvenuto A, Fasano A, Alcon AG, Kraneveld A, et al. Risk and Protective Environmental Factors Associated with Autism Spectrum Disorder: Evidence-Based Principles and Recommendations. J Clin Med. 2019;8(2):217. https://doi.org/10.3390/jcm8020217

31. Hagmeyer S, Mangus K, Boeckers TM, Grabrucker AM. Effects of trace metal profiles characteristic for autism on synapses in cultured neurons. Neural Plast. 2015;2015: 985083. https://doi. org/10.1155/2015/985083

32. Careaga M, Murai T, Bauman MD. Maternal Immune Activation and Autism Spectrum Disorder: From Rodents to Nonhuman and Human Primates. Biol Psychiatry. 2017;81(5):391-401. https://doi. org/10.1016/j.biopsych.2016.10.020

33. Bölte S, Girdler S, Marschik PB. The contribution of environmental exposure to the etiology of autism spectrum disorder. Cell Mol Life Sci. 2019;76(7):1275-97. https://doi.org/10.1007/ s00018-018-2988-4

34. Jyonouchi H, Sun S, Le H. Proinflammatory and regulatory cytokine production associated with innate and adaptive immune responses in children with autism spectrum disorders and developmental regression. J Neuroimmunol. 2001;120(1-2):170-9. https://doi.org/10.1016/S0165-5728(01)00421-0 
35. Malik M, Sheikh AM, Wen G, Spivack W, Brown WT, Li X. Expression of inflammatory cytokines, Bcl2 and cathepsin D are altered in lymphoblasts of autistic subjects. Immunobiology. 2011;216(1-2):80-5. https://doi.org/10.1016/j.imbio.2010.03.001

36. Vargas DL, Nascimbene C, Krishnan C, Zimmerman AW, Pardo CA. Neuroglial activation and neuroinflammation in the brain of patients with autism. Ann Neurol. 2005;57(1):67-81. https://doi. org/10.1002/ana.20315

37. Modabbernia A, Velthorst E, Reichenberg A. Environmental risk factors for autism: an evidencebased review of systematic reviews and meta-analyses. Mol Autism. 2017;8(1):1-16. https://doi. org/10.1186/s13229-017-0121-4

38. Matelski L, Van de Water J. Risk factors in autism: Thinking outside the brain. J Autoimmun. 2016;67:1-7. https://doi.org/10.1016/j.jaut.2015.11.003

39. Haar S, Berman S, Behrmann M, Dinstein I. Anatomical Abnormalities in Autism? Cereb Cortex. 2016;26(4):1440-52. https://doi.org/10.1093/cercor/bhu242

40. Nickl-Jockschat T, Habel U, Maria Michel T, Manning J, Laird AR, Fox PT, et al. Brain structure anomalies in autism spectrum disorder-a meta-analysis of VBM studies using anatomic likelihood estimation. Hum Brain Mapp. 2012;33(6):1470-89. https://doi.org/10.1002/hbm.21299

41. Courchesne E, Campbell K, Solso S. Brain growth across the life span in autism: Age-specific changes in anatomical pathology. Brain Res. 2011;1380:138-45. https://doi.org/10.1016/j.brainres.2010.09.101

42. Mohammad-Rezazadeh I, Frohlich J, Loo SK, Jeste SS. Brain connectivity in autism spectrum disorder. Casanova MF, El-Baz A, Suri JS, editors. Curr Opin Neurol. 2016;29(2):137-47. https://doi. org/10.1097/WCO.0000000000000301

43. Fatemi SH, Aldinger KA, Ashwood P, Bauman ML, Blaha CD, Blatt GJ, et al. Consensus paper: Pathological role of the cerebellum in Autism. Cerebellum 2012;11(3):777-807. https://doi. org/10.1007/s12311-012-0355-9

44. Durand CM, Betancur C, Boeckers TM, Bockmann J, Chaste P, Fauchereau F, et al. Mutations in the gene encoding the synaptic scaffolding protein SHANK3 are associated with autism spectrum disorders. Nat Genet. 2007;39(1):25-7. https://doi.org/10.1038/ng1933

45. Leblond CS, Nava C, Polge A, Gauthier J, Huguet G, Lumbroso S, et al. Meta-analysis of SHANK Mutations in Autism Spectrum Disorders: A Gradient of Severity in Cognitive Impairments. PLoS Genet. 2014;10(9): e1004580. https://doi.org/10.1371/journal.pgen.1004580

46. Moessner R, Marshall CR, Sutcliffe JS, Skaug J, Pinto D, Vincent J, et al. Contribution of SHANK3 mutations to autism spectrum disorder. Am J Hum Genet. 2007;81(6):1289-97. https://doi. org/10.1086/522590

47. Autism Genome Project Consortium, Szatmari P, Paterson AD, Zwaigenbaum L, Roberts W, Brian J, et al. Mapping autism risk loci using genetic linkage and chromosomal rearrangements. Nat Genet. 2007;39(3):319-28. https://doi.org/10.1038/ng1985

48. Kim H-G, Kishikawa S, Higgins AW, Seong I-S, Donovan DJ, Shen Y, et al. Disruption of Neurexin 1 Associated with Autism Spectrum Disorder. Am J Hum Genet [Internet] . 2008;82(1):199-207. https:// doi.org/10.1016/j.ajhg.2007.09.011

49. Yan J, Noltner K, Feng J, Li W, Schroer R, Skinner C, et al. Neurexin $1 \alpha$ structural variants associated with autism. Neurosci Lett. 2008;438(3):368-70. https://doi.org/10.1016/j.neulet.2008.04.074

50. De Rubeis S, He X, Goldberg AP, Poultney CS, Samocha K, Ercument Cicek A, et al. Synaptic, transcriptional and chromatin genes disrupted in autism. Nature. 2014;515(7526):209-15. https://doi. org/10.1038/nature 13772

51. Parente DJ, Garriga C, Baskin B, Douglas G, Cho MT, Araujo GC, et al. Neuroligin 2 nonsense variant associated with anxiety, autism, intellectual disability, hyperphagia, and obesity. Am J Med Genet Part A. 2017;173(1):213-6. https://doi.org/10.1002/ajmg.a.37977

52. Xu X, Xiong Z, Zhang L, Liu Y, Lu L, Peng Y, et al. Variations analysis of NLGN3 and NLGN4X gene in Chinese autism patients. Mol Biol Rep. 2014;41(6):4133-40. https://doi.org/10.1007/ s11033-014-3284-5

53. Jamain S, Quach H, Betancur C, Råstam M, Colineaux C, Gillberg C, et al. Mutations of the X-linked genes encoding neuroligins NLGN3 and NLGN4 are associated with autism. Nat Genet. 2003;34(1):27-9. https://doi.org/10.1038/ngl136 
54. Bourgeron T. Les connaissances actuelles sur la génétique de l'autisme et propositions pour la recherche future. Comptes Rendus - Biol. 2016;339(7-8):300-7. https://doi.org/10.1016/j.crvi.2016.05.004

55. Huguet G, Ey E, Bourgeron T. The Genetic Landscapes of Autism Spectrum Disorders. Annu Rev Genomics Hum Genet. 2013;14:191-213. https://doi.org/10.1146/annurev-genom-091212-153431

56. Bagni C, Zukin RS. A Synaptic Perspective of Fragile X Syndrome and Autism Spectrum Disorders. Neuron 2019;101(6):1070-1088. https://doi.org/10.1016/j.neuron.2019.02.041

57. Guang S, Pang N, Deng X, Yang L, He F, Wu L, et al. Synaptopathology involved in autism spectrum disorder. Front Cell Neurosci. 2018;12:1-16. https://doi.org/10.3389/fncel.2018.00470

58. Bourgeron T. A synaptic trek to autism. Curr Opin Neurobiol. 2009;19(2):231-4. https://doi. org/10.1016/j.conb.2009.06.003

59. Grabrucker AM, Schmeisser MJ, Schoen M, Boeckers TM. Postsynaptic ProSAP/Shank scaffolds in the cross-hair of synaptopathies. Trends Cell Biol. 2011;21(10):594-603. https://doi.org/10.1016/j. tcb.2011.07.003

60. Grabrucker AM. Environmental factors in autism. Front Psychiatry. 2013;3:1-13. https://doi. org/10.3389/fpsyt.2012.00118

61. Buie T, Campbell DB, Fuchs GJ, Furuta GT, Levy J, VandeWater J, et al. Evaluation, diagnosis, and treatment of gastrointestinal disorders in individuals with ASDs: a consensus report. Pediatrics. 2010;125 Suppl 1:1-18. https://doi.org/10.1542/peds.2009-1878C

62. Adams JB, Johansen LJ, Powell LD, Quig D, Rubin RA. Gastrointestinal flora and gastrointestinal status in children with autism - comparisons to typical children and correlation with autism severity. BMC Gastroenterol. 2011;11(1):22. https://doi.org/10.1186/1471-230X-11-22

63. Bjørklund G, Pivina L, Dadar M, Meguid NA, Semenova Y, Anwar M, et al. Neuroscience and Biobehavioral Reviews Gastrointestinal alterations in autism spectrum disorder : What do we know? Neurosci Biobehav Rev. 2020;118:111-20. https://doi.org/10.1016/j.neubiorev.2020.06.033

64. Wasilewska J, Klukowski M. Gastrointestinal symptoms and autism spectrum disorder: links and risks \&ndash; a possible new overlap syndrome. Pediatr Heal Med Ther. 2015;6:153-166. https://doi. org/10.2147/PHMT.S85717

65. Wang LW, Tancredi DJ, Thomas DW. The prevalence of gastrointestinal problems in children across the United States with autism spectrum disorders from families with multiple affected members. J Dev Behav Pediatr. 2011;32(5):351-60. https://doi.org/10.1097/DBP.0b013e31821bd06a

66. de Magistris L, Familiari V, Pascotto A, Sapone A, Frolli A, Iardino P, et al. Alterations of the intestinal barrier in patients with autism spectrum disorders and in their first-degree relatives. J Pediatr Gastroenterol Nutr. 2010;51(4):418-24. https://doi.org/10.1097/MPG.0b013e3181dcc4a5

67. D’Eufemia P, Celli M, Finocchiaro R, Pacifico L, Viozzi L, Zaccagiiini M, et al. Abnormal intestinal permeability in children with autism. Acta Paediatr 1996;85(9):1076-9. https://doi. org/10.1111/j.1651-2227.1996.tb14220.x

68. Hsiao EY, McBride SW, Chow J, Mazmanian SK, Patterson PH. Modeling an autism risk factor in mice leads to permanent immune dysregulation. Proc Natl Acad Sci USA. 2012;109(31):12776-81. https:// doi.org/10.1073/pnas.1202556109

69. Fröhlich H, Kollmeyer ML, Linz VC, Stuhlinger M, Groneberg D, Reigl A, et al. Gastrointestinal dysfunction in autism displayed by altered motility and achalasia in Foxpl +/- mice. Proc Natl Acad Sci USA. 2019;116(44):22237-45. https://doi.org/10.1073/pnas.1911429116

70. James DM, Kozol RA, Kajiwara Y, Wahl AL, Storrs EC, Buxbaum JD, et al. Intestinal dysmotility in a zebrafish (Danio rerio) shank3a;shank3bmutant model of autism. Mol Autism 2019;10:3. https://doi. org/10.1186/s13229-018-0250-4

71. Mayer E a, Knight R, Mazmanian SK, Cryan JF, Tillisch K. Gut microbes and the brain: paradigm shift in neuroscience. J Neurosci. 2014;34(46):15490-6. https://doi.org/10.1523/JNEUROSCI.3299-14.2014

72. De Angelis M, Piccolo M, Vannini L, Siragusa S, De Giacomo A, Serrazzanetti DI, et al. Fecal Microbiota and Metabolome of Children with Autism and Pervasive Developmental Disorder Not Otherwise Specified. PLoS One. 2013;8(10):1-18. https://doi.org/10.1371/journal.pone.0076993

73. Finegold SM, Dowd SE, Gontcharova V, Liu C, Henley KE, Wolcott RD, et al. Pyrosequencing study of fecal microflora of autistic and control children. Anaerobe. 2010;16(4):444-53. https://doi. org/10.1016/j.anaerobe.2010.06.008 
74. Kang DW, Park JG, Ilhan ZE, Wallstrom G, LaBaer J, Adams JB, et al. Reduced Incidence of Prevotella and Other Fermenters in Intestinal Microflora of Autistic Children. PLoS One 2013;8(7):e68322. https://doi.org/10.1371/journal.pone.0068322

75. Kang DW, Adams JB, Gregory AC, Borody T, Chittick L, Fasano A, et al. Microbiota Transfer Therapy alters gut ecosystem and improves gastrointestinal and autism symptoms: An open-label study. Microbiome. 2017;5(1):1-16. https://doi.org/10.1186/s40168-016-0225-7

76. Kang DW, Ilhan ZE, Isern NG, Hoyt DW, Howsmon DP, Shaffer M, et al. Differences in fecal microbial metabolites and microbiota of children with autism spectrum disorders. Anaerobe. 2018;49(2018):121-31. https://doi.org/10.1016/j.anaerobe.2017.12.007

77. Vela G, Stark P, Socha M, Sauer AK, Hagmeyer S, Grabrucker AM. Zinc in Gut-Brain Interaction in Autism and Neurological Disorders. Neural Plast 2015;2015:972791. https://doi.org/10.1155/2015/972791

78. Coretti L, Paparo L, Riccio MP, Amato F, Cuomo M, Natale A, et al. Gut microbiota features in young children with autism spectrum disorders. Front Microbiol. 2018;9:1-12. https://doi.org/10.3389/ fmicb.2018.03146

79. de Angelis M, Francavilla R, Piccolo M, De Giacomo A, Gobbetti M. Autism spectrum disorders and intestinal microbiota. Gut Microbes. 2015;6(3):207-13. https://doi.org/10.1080/19490976.2015.10 35855

80. Kong X, Liu J, Cetinbas M, Sadreyev R, Koh M, Huang H, et al. New and preliminary evidence on altered oral and gut microbiota in individuals with autism spectrum disorder (ASD): Implications for ASD diagnosis and subtyping based on microbial biomarkers. Nutrients. 2019;11(9). https://doi. org/10.3390/nul1092128

81. Strati F, Cavalieri D, Albanese D, De Felice C, Donati C, Hayek J, et al. New evidences on the altered gut microbiota in autism spectrum disorders. Microbiome. 2017;5(1):24. https://doi.org/10.1186/ s40168-017-0242-1

82. Williams BL, Hornig M, Buie T, Bauman ML, Cho Paik M, Wick I, et al. Impaired carbohydrate digestion and transport and mucosal dysbiosis in the intestines of children with autism and gastrointestinal disturbances. PLoS One. 2011;6(9):e24585. https://doi.org/10.1371/journal.pone.0024585

83. Liu F, Li J, Wu F, Zheng H, Peng Q, Zhou H. Altered composition and function of intestinal microbiota in autism spectrum disorders: a systematic review. Transl Psychiatry. 2019;9(1):43. https://doi. org/10.1038/s41398-019-0389-6

84. Cryan JF, O'Riordan KJ, Cowan CSM, Sandhu K V, Bastiaanssen TFS, Boehme M, et al. The MicrobiotaGut-Brain Axis. Physiol Rev. 2019;99(4):1877-2013. https://doi.org/10.1152/physrev.00018.2018

85. Rogers GB, Keating DJ, Young RL, Wong M-L, Licinio J, Wesselingh S. From gut dysbiosis to altered brain function and mental illness: mechanisms and pathways. Mol Psychiatry. 2016;21(6):738-48. https://doi.org/10.1038/mp.2016.50

86. Leigh JP, Du J. Brief Report: Forecasting the Economic Burden of Autism in 2015 and 2025 in the United States. J Autism Dev Disord. 2015;45(12):4135-9. https://doi.org/10.1007/s10803-015-2521-7 
